\title{
INTERPRETAÇÃO DO DIREITO E TEORIAS DA VERDADE
}

José Ricardo Alvarez Vianna ${ }^{1}$

\section{Resumo}

Interpretar o Direito consiste em atribuir sentido aos vocábulos contidos nos textos normativos. Nem por isto a interpretação deve se realizar com base nas convicções pessoais do intérprete; deve, antes, estar ancorada em uma racionalidade jurídica consistente. Os métodos da hermenêutica jurídica (gramatical, lógico, histórico, finalístico, sistemático etc.) não apresentam hierarquia entre si, o que possibilita ao intérprete a adoção de um método em vez de outro, o que pode levar a soluções jurídicas diferentes para o mesmo caso. As teorias da verdade (correspondência, pragmática e consensual) fornecem elementos para uma racionalidade jurídica na interpretação do Direito. O intérprete deve buscar a verdade consensual vigente na comunidade jurídica em relação ao instituto em exame. A verdade pragmática, constituída a partir das crenças do intérprete, deve ser refutada. As teorias da verdade aplicadas à interpretação do Direito auxiliam o intérprete em sua atividade e proporcionam referenciais firmes para aquilatar a razoabilidade da interpretação realizada.

Palavras-Chave: Interpretação do Direito. Teorias da Verdade. Filosofia da Linguagem.

\section{INTRODUÇÃO}

Interpretar o Direito é tema amplo e enseja múltiplas abordagens, motivo pelo qual traz implícita uma série de aspectos polêmicos e de relevância ímpar para a sociedade. Diz-se isto porque é por meio da interpretação que a norma jurídica passa de sua conformação geral e abstrata para individual e concreta, a fim de solucionar o problema jurídico em desate.

Atento a isto, o objetivo geral do artigo busca, inicialmente, realizar uma abordagem panorâmica de alguns pontos concernentes à interpretação jurídica. Neste ponto, procurará desfazer alguns equívocos relativos à interpretação jurídica com o intuito de deixar claro em que consiste esta atividade.

O objetivo específico, por sua vez, visa traçar uma conexão entre interpretação jurídica e teorias da verdade. Para este desiderato serão detalhadas quais são as espécies de verdade, de acordo com a Filosofia, e como estas podem contribuir no processo de interpretação do Direito, de maneira a obstar eventual discricionariedade demasiada do intérprete, circunstância que pode colocar em risco a segurança jurídica e a higidez do sistema

\footnotetext{
${ }^{1}$ Doutor em Ciências Jurídico-Políticas pela Faculdade de Direito da Universidade de Lisboa (FDUL). Professor da Escola da Magistratura do Paraná. Professor na Universidade Estadual de Londrina, pós-graduação lato sensu. E-mail: jricardo9926@gmail.com
} 
jurídico.

Em nível de problematização, o artigo se propõe a responder à questão: a compreensão das teorias da verdade - especificamente verdade por correspondência, verdade pragmática e verdade consensual - podem contribuir para a racionalidade no processo de interpretação do Direito?

Um olhar atento ao problema levantado, contudo, revela que para se alcançar uma resposta satisfatória à pergunta formulada, será preciso esclarecer outros tópicos que lhe são correlatos, tais como: o que deve ser entendido por interpretação jurídica? Os métodos tradicionais da hermenêutica jurídica fornecem padrões para impedir soluções ad hoc? O que caracteriza uma boa teoria da interpretação jurídica? Existe verdade nesta espécie de interpretação?

Para desenvolvimento do artigo houve enfoque normativo, haja vista ser a lei uma das principais fontes do Direito no Brasil. Aliado a isso, foi realizada pesquisa interdisciplinar, abrangendo Direito e Filosofia, consultando-se obras nacionais e estrangeiras em ambas as áreas. Foram, também, analisados julgados que se revelaram pertinentes à concatenação do raciocínio trabalhado.

\section{INTERPRETAÇÃO DO DIREITO, LINGUAGEM, RACIONALIDADE JURÍDICA}

O ser humano não suporta o caos. Em razão disto, atribui sentido a tudo com o que se depara. Ao dar sentido aos fenômenos e acontecimentos no mundo que o cerca, o sujeito tem a sensação de segurança, pressuposto necessário para seguir adiante em sua jornada.

Umberto Eco (1997, p. 55) cita interessante passagem de Marco Polo, a qual, de certo modo, expressa o que se pretende dizer. Eco relata que Polo, ao longo de suas viagens, teria se deparado com um rinoceronte, animal que the era totalmente estranho, já que em Veneza, terra natal do explorador, não havia rinocerontes. Seja como for, Polo não hesitou em dar um sentido ao animal diante de si. Após notar que se tratava de um quadrúpede e com um chifre logo acima do nariz, não tardou em concluir que, obviamente, tratava-se de um unicórnio, o que lhe amainou o espírito. Na sequência, o veneziano teria acrescentado: não é um animal belo, branco e dócil como descrito nas lendas remotas. Bem ao contrário, consistia em uma fera desgraciosa, com pelos de búfalo, pés de elefante, língua espinhosa e cabeça semelhante à de um javali; enfim, "uma besta muito feia de se ver".

A passagem é sintomática. Para o ser humano é indispensável que exista uma razão, uma coerência, uma lógica no mundo para que ele possa lidar com os riscos e incertezas da vida; com a imponderabilidade da vida.

Isto também se dá na interpretação jurídica. Afinal, o ser humano é um ser interpretante por natureza; precisa compreender as normas jurídicas, encontrar uma coerência e ordenação nestas. As normas jurídicas precisam ter um sentido, uma finalidade.

É importante sublinhar que esta postura interpretativa é intrínseca à linguagem. Num primeiro aporte, 
pode-se pensar que a linguagem se circunscreve à comunicação entre as pessoas. Esta é uma visão limitada, porém. Antes de ocorrer a comunicação, o sujeito cognoscente interpreta a realidade, as palavras, os signos que afluem diante de si para só então the atribuir sentido, o que é feito a partir de suas percepções sensoriais e de sua biografia, tal como ocorreu com Marco Polo. Somente vencida esta etapa - significação - é que poderá haver comunicação, entendida como o compartilhamento dos significados firmados.

Para os fins do presente artigo, toma-se o Direito como um conjunto de normas estabelecidas para organizar e possibilitar o convívio social harmonioso. Tais normas, por certo, serão objeto de interpretação; especificamente, de interpretação jurídica.

Mas o que vem a ser interpretação jurídica?

Para Fernando Capez (2012, p. 105) "é a atividade que consiste em extrair da norma seu exato alcance e real significado".

Capez não está só nesta visão. Bem antes dele, em obra clássica do Direito brasileiro, publicada em meados do Século XIX, o Barão de Ramalho (1984, p. 97) já pontuava: "interpretação é a exposição do verdadeiro sentido de uma lei obscura em sua redação, silenciosa ou duvidosa aos fatos ocorrentes".

Este modo de ver a interpretação jurídica está atrelado ao vocábulo "hermenêutica", palavra oriunda do grego (hermēneuein) e que significa revelar, declarar, esclarecer, traduzir, compreender etc. É sabido que o vocábulo hermenêutica adveio de Hermes que, na mitologia grega, é filho de Zeus com Maia, e a quem incumbia levar as mensagens dos deuses aos homens, tornando-as compreensíveis. Como os homens não falavam diretamente com os deuses, Hermes era o intermediário de ambos (BLEICHER, 1992, p. 23).

Sob este prisma, a atividade de interpretação manifesta-se de maneira objetiva, uma vez que cabe ao intérprete identificar o significado preciso das palavras contidas na lei para aplicá-la de forma correta. Este, aliás, foi o modelo adotado por Montesquieu, ao formular a teoria da separação dos poderes que orientou a formação do Estado pós-revoluções burguesas. Para Montesquieu (1892, p. 238), ao proferir suas decisões, o Poder Judiciário, invisível e nulo, em sua atividade interpretativa do Direito, nada mais fazia do que pronunciar as palavras da lei, daí por que o juiz se restringia a ser a boca da lei.

Os adágios latinos in claris cessat interpretatio e in claris non fit interpretatio, oriundos do remoto direito romano e segundo os quais, quando a lei é clara não há necessidade de interpretação, já trilhava por este caminho. No entanto, não obstante toda a edificação empreendida sob este formato, indaga-se: será mesmo isto o que se dá na interpretação jurídica? Os profissionais do Direito sejam eles advogados, promotores, juízes, professores, delegados de polícia, no exercício de suas funções, apenas extraem da lei sua extensão precisa e seu correto sentido?

Pois bem. De acordo com a filosofia da linguagem, a resposta é negativa. Por outras palavras, a 
interpretação jurídica não se limita a colher da lei inequívoca extensão e genuíno significado. Um olhar atento ao tema evidencia que interpretar o Direito consiste em atribuir sentido aos vocábulos existentes nos textos jurídicos; nas palavras que constituem e torneiam determinado instituto jurídico. Mesmo nos casos em que a norma jurídica é pretensamente clara, subsiste no ato de interpretar a outorga de um significado. Não há, pois, um sentido intrínseco, inflexível e imutável nos textos normativos jurídicos.

Isto ocorre porque a linguagem é marcada pela vagueza e ambiguidade. Vagueza corresponde à imprecisão dos vocábulos. Por exemplo: quando se diz que o veículo estava em alta velocidade ou que o jantar vai demorara ser servido, não há condições suficientes para uma comunicação isenta de dúvidas. Palavras como alto e demorarsão obscuras para se compreender, de modo objetivo, o teor da mensagem.

Ambiguidade, por outro lado, refere-se à polissemia; aos vários significados que um vocábulo pode ter. A palavra direito é exemplo disso. Pode tanto indicar determinada posição espacial em oposição a esquerdo, como algo supostamente correto em contraposição a errado. Pode designar, também, conjunto de normas jurídicas. A ambiguidade, assim como a vagueza, dificulta a comunicação diante dos múltiplos significados de uma mesma palavra.

Para tornar tais afirmações mais palpáveis, bem como situá-las na esfera jurídica, convém trazer alguns exemplos. Toma-se, então, por base o Direito Penal, no qual prevalece a chamada tipicidade cerrada, cuja interpretação deve ser restritiva.

Neste sentido, recorre-se ao artigo 233 do Código Penal, o qual prevê o crime de ato obsceno, mediante a seguinte redação: "praticar ato obsceno em lugar público, ou aberto ou exposto ao público. Pena: detenção, de três meses a um ano, ou multa".

Após breve leitura do texto legal transcrito não é preciso muito esforço para se notar que não há como escapar, no processo interpretativo, da atribuição de significado aos vocábulos empregados. Sim, porque o que se pode entender por ato obsceno? O que vem a ser lugar público? Ou: o que é lugar aberto ou exposto ao público?

Como se infere, não há um conceito dado, pronto, acabado, mesmo quando a interpretação deva se efetivar em tons restritivos. Em maior ou menor escala, haverá a constituição de significado do texto a partir do contexto fático e social respectivo. Basta lembrar que nem todas condutas que poderiam ser consideradas obscenas em $1^{\circ}$ de janeiro de 1942, data de início de vigência do Código Penal, certamente, o serão ao longo da década iniciada em 2010.

A propósito, em 2004, o Supremo Tribunal Federal viu-se na contingência de interpretar o artigo 233 do Código Penal. Na ocasião, concluiu que a conduta do diretor Gerald Thomas, em 2003, no Teatro Municipal do Rio de Janeiro, ao mostrar suas nádegas ao público e simular gestos de masturbação em reação às vaias da plateia à peça por ele dirigida, não configurava crime ato obsceno. $\mathrm{Na}$ interpretação do STF, embora inadequada e 
grosseira, a conduta foi apenas uma resposta ao público presente, circunstância que se inseria no conceito de liberdade de manifestação. Além disso, não ficou demonstrada intenção sexual, o que reafirmava a conclusão firmada. ${ }^{2}$

A palavra "idoso" é outro exemplo. Se alguém perguntar quem pode ser considerado idoso, a resposta, a princípio, será simples, já que o artigo 1º da Lei no 10.741/2003 (Estatuto do Idoso), é taxativo ao dizer que são idosas as pessoas com idade igual ou superior a 60 (sessenta) anos.

Apesar disso, não há como dizer que é sempre assim. Em certa ocasião, extraída da vivência jurídica profissional, 2 (dois) candidatos permaneciam empatados após as provas e a contagem dos títulos em concurso público para oficial de Registro de Imóveis. Mesmo após a utilização dos critérios ordinários de desempate, o empate permanecia. Como último critério, havia a seguinte regra: caso persista o empate, será nomeado o candidato mais idoso.

Sucede que ambos candidatos sequer contavam 50 (cinquenta) anos de idade. Um estava com 49 (quarenta e nove), enquanto o outro com 47 (quarenta e sete) anos. A vaga ficou para o candidato com 49 (quarenta e nove) anos. Logo, nem sempre idoso será quem tem idade igual ou superior a 60 (sessenta) anos. O significado do vocábulo idoso contido em textos normativos pode, conforme o caso, carecer de interpretação, e este processo de significação não se dá necessariamente de modo unívoco.

O tema ainda pode tomar dimensões mais amplas quando se estiver diante de textos que contenham conceitos jurídicos indeterminados ou quando se tratar de princípios jurídicos.

Para se atestar isto, basta um rápido olhar em alguns dispositivos legais, caso do artigo 157 do Código Civil, que trata do instituto da lesão. Consoante este dispositivo: "ocorre a lesão quando uma pessoa, sob premente necessidade, ou por inexperiência, se obriga a prestação manifestamente desproporcional ao valor da prestação oposta”.

Mas o que vem a ser premente necessidade? O que se entende por inexperiência? E por manifestamente desproporcional?

O Código de Processo Civil de 2015, segue semelhante itinerário. Ao dispor sobre as hipóteses de inversão do ônus da prova, o $\$ 1^{\circ}$, do art. 373, firmou:

Art. 373. Nos casos previstos em lei ou diante de peculiaridades da causa relacionadas à impossibilidade ou à excessiva dificuldade de cumprir o encargo nos termos do caput ou à maior facilidade de obtenção da prova do fato contrário, poderá o juiz atribuir o ônus da prova de modo diverso, desde que o faça por decisão fundamentada, caso em que deverá dar à parte a oportunidade de se desincumbir do ônus que lhe foi atribuído.

\footnotetext{
${ }^{2}$ BRASIL. Supremo Tribunal Federal. Habeas Corpus no 83996-RJ. Paciente: Gerald Thomas Sievers. Impetrante: Paulo Freitas Ribeiro. Relator: Ministro Carlos Velloso. Brasília, 17 de agosto de 2004 . Disponível em: <http://www.stf.jus.br/portal/processo/verProcessoAndamento.asp?numero=83996\&classe=HC\&origem=AP\&recurso=0\&tip oJulgamento=M $>$. Acessado em: 03 mar. 2017.
} 
A partir de aludido enunciado, perquire-se: o que se deve entender por excessiva dificuldade ou por maior facilidade em obter a prova do fato?

Seguramente, não existe uma resposta matemática para tais vocábulos. Eles carecem de interpretação, de densificação quanto a seu conteúdo.

Não é só.

Raciocínio similar se aplica e com maior intensidade aos princípios jurídicos. Basta relembrar de princípios como devido processo legal, dignidade da pessoa humana, insignificância no Direito Penal ou anterioridade tributária. Dada a generalidade como os princípios costumam figurar em normas jurídicas, não há como escapar do processo de imputação de sentido para que possam ser aplicados. Vale dizer: a atribuição de significados pelo intérprete é uma constante; invariavelmente, está presente, em maior ou menor escala.

Antes de prosseguir, é imperioso registrar que não é o caso de suprimir do plano normativo os conceitos jurídicos abertos. Em rigor, esses conceitos são necessários à operabilidade do sistema jurídico. A ideia de completude do ordenamento jurídico desde longa data está vencida, uma vez que não há como o legislador antever todas as situações da vida dada sua dinamicidade, atrelada à contínua mudança de valores compartilhados em sociedade. De igual modo, não se revela sensata, como alerta Bobbio (1999, p. 121), a suposição de que a lei seja para o juiz nada mais do que um prontuário a ser consultado e do qual ele não deve se afastar jamais, o que equivaleria a uma espécie de fetichismo da lei.

Além do mais, mesmo que as leis fossem casuísticas, formatadas na fórmula se $X$, então $Y$, ainda assim haveria a vagueza e ambiguidade das palavras, como visto no exemplo do crime de ato obsceno, o que exige do intérprete a constituição de sentido para sua efetivação.

Por isto, o que se busca é um método que contenha em si uma racionalidade jurídica no processo interpretativo do Direito, de maneira a evitar o arbítrio do intérprete no processo de significação. Um modelo que preserve a estrutura orgânica do Direito, estrutura esta que lhe confere status de sistema, constituído mediante um conjunto relações de coordenação e subordinação entre as normas que compõem o ordenamento jurídico.

Por certo, não se ignora que a hermenêutica jurídica contém métodos para dar cabo à interpretação, caso do método gramatical, lógico, teleológico, histórico, sistemático, dentre outros. Entretanto, não há hierarquia entre tais métodos e isto permite ao intérprete optar por um método em vez de outro. Isto se torna problemático porque, conforme o método aplicado, a solução jurídica pode receber desfecho diferente (ALEXY, 2012, p. 25).

Recaséns Siches (1973, p. 165) cita exemplo que confirma esta face dúctil da interpretação jurídica. Trata-se de regra existente em uma estação ferroviária fictícia, assim redigida: "é proibida a entrada na plataforma de pessoas com cães". Observe que se for adotada a interpretação literal, não haverá óbice de alguém ingressar no local com um leão. Em contrapartida, se o intérprete adotar interpretação finalística, a proibição será de rigor, haja 
vista o risco à segurança e integridade física dos presentes. ${ }^{3}$

Este aspecto ganha relevância na medida em que a escolha dos métodos de interpretação pode acomodar, de maneira velada, preferências pessoais do intérprete e, por conseguinte, contribuir para um cenário de instabilidade jurídica.

Para atenuar esta flexibilidade interpretativa no campo jurídico, tem-se que as teorias da verdade, concebidas e articuladas no âmbito da Filosofia, podem prestar relevante contribuição. Isto porque, além de mitigarem a discricionariedade no ato de interpretar, ainda fornecerão padrões ao intérprete para conduzir seu percurso significativo, bem como referenciais para quem se interessar em examinar a razoabilidade da solução jurídica advinda da interpretação, como será visto de modo mais detalhado adiante.

\section{UMA BOA TEORIA INTERPRETATIVA PARA O DIREITO}

A alusão ao adjetivo boa no título desta seção é proposital. A intenção é despertar no leitor a reflexão do que pode ser considerada uma boa teoria de interpretação jurídica no sentido de sua eficiência. Antes, porém, é preciso ter presente o que se entende por teoria.

Com efeito, as teorias procuram explicar determinados fenômenos. De posse desse conhecimento, sabedor das propriedades, características, reações, configurações do objeto estudado, haverá possibilidade de se lidar com ele.

Uma boa teoria, então, será aquela que não varia em demasia quanto às explicações propostas; que não contenham soluções ad hoc apenas para atender à demanda de respostas sem compromisso com a essência do objeto estudado.

David Deutsch, em The Beginnig of Infinity (2011, p. 19-22), vai buscar na mitologia grega exemplo para demonstrar o que pode ser considerada uma boa e uma máteoria. Como se sabe, a mitologia grega valia-se de uma série de lendas e alegorias para explicar o universo, a vida, a origem da vida, os eventos naturais etc. Deutsch destaca que, para explicar as estações do ano, os gregos se valiam do mito de Perséfone e Hades. Perséfone, deusa da primavera, era filha de Deméter com Zeus. Deméter era a deusa da agricultura e velava pela fertilidade da terra, bom plantio e colheita; enquanto Zeus era o senhor do Olimpo. Já Hades era o deus do mundo inferior, do submundo.

Certo dia, Hades raptou Perséfone por quem se apaixonou. Deméter, inconformada com a situação, foi até Hades para resgatar a filha, mas já era tarde. Perséfone já havia comido sementes de romã (magic seed) e não mais poderia retornar. Deméter, para não se afastar da filha, não retornou ao Olimpo e no período em que esteve

\footnotetext{
${ }^{3} \mathrm{O}$ recorte ao pensamento de Siches se justifica apenas para a coleta de exemplo veiculado, sem que isto importe fazer alusão à
} 
fora houve escassez de alimentos diante da pouca fertilidade da terra. Preocupado com esse quadro, Zeus interveio e firmou acordo com Hades, no qual Perséfone poderia retornar com a mãe, desde que, durante 1/3 (um terço) do ano, permanecesse com Hades no submundo. O período em que Perséfone estivesse no submundo corresponderia à estação do inverno, pois Deméter estaria triste pela ausência da filha, não conseguindo desempenhar sua função de auxílio no plantio e colheita.

Para David Deutsch esta é uma explicação fraca, eis que não esclarece uma série de variações que podem ocorrer no curso das estações do ano, além de não detalhar as circunstâncias do suposto acordo entre Hades e Zeus, o que conduz a explicações ad hoc, as quais variam facilmente (easily variable), conforme a óptica. Além do mais, se os gregos conhecessem a Austrália não conseguiriam aplicar a explicação mitológica para as estações do ano, eis que na Oceania estas se manifestam em datas diversas da Europa.

Explicações deste jaez, a bem ver, nada explicam. Dependerão dos valores de quem estiver com a palavra, além de que não poderão ser testadas satisfatoriamente, o que conduz à sua fluidez.

Com base nisto, Deutsch (2011, p. 24) afirma que uma boa explicação científica deve ser difícil de variar (hard to vary). Em complemento a seu raciocínio, ele cita o movimento de translação da Terra durante 1 (um) ano em torno do Sol. Se for considerada a inclinação da Terra diante do Sol, ficam explicadas satisfatoriamente as estações do ano, em qualquer parte do planeta. Está-se, assim, diante de uma boa explicação, visto que é difícil de variar.

Não é difícil estabelecer conexão entre os comentários de David Deutsch e a interpretação jurídica. A interpretação jurídica, para ser considerada sólida ( boa), não pode acomodar soluções múltiplas e diametralmente opostas entre si, sobretudo se isto se prestar a encobrir valores do intérprete. Se assim for, estar-se-á frente a uma teoria fraca, dada sua volubilidade.

Em síntese, uma boa teoria é aquela que pouco varia em sua aplicação; que se pauta por critérios objetivos; que evita soluções de momento e de acordo com juízos do intérprete. Uma boa teoria será aquela que confere segurança e credibilidade à explicação apresentada em relação ao fenômeno examinado.

Demarcadas estas premissas, tem-se que as teorias da verdade podem ser reputadas boas se aplicadas à interpretação jurídica, como será visto a seguir.

\section{TEORIAS DA VERDADE}

A verdade ocupa posição de destaque na Filosofia. A verdade é uma aspiração e uma necessidade para o ser humano. Será a convicção de se estar diante da verdade que o indivíduo articula a realidade e identifica um 
sentido em sua vida. Mais do que isso. É com base em verdades que a vida em sociedade flui em suas mais diversas dimensões. Verdades ditam a forma como equipamentos de segurança são projetados, como protocolos médicos são editados, como padrões educacionais são firmados.

No Direito não é diferente. A verdade orienta e justifica, por exemplo, um tratamento jurídico diferenciado para pessoas em peculiar estado, caso de crianças, idosos e portadores de deficiência. A verdade, igualmente, sinaliza como determinadas lides serão decididas judicialmente. Em suma, condutas são praticadas segundo parâmetros de verdade.

Sem embargo do que foi dito, como se pode falar em verdade em sociedades plúrimas de valores, costumes, crenças como ocorre nos regimes democráticos?

Antes disso: o que é verdade?

Para dar cabo a estas indagações, a Filosofia, ao longo dos Séculos, encarregou-se de formular algumas teorias sobre a verdade. De partida, averbe-se que não há na Filosofia uma teoria da verdade, mas várias. A verdade pode advir dos sentidos, caso da visão, tato, audição, olfato e paladar (realidade cognoscível), como de crenças e valores individuais; de intuições e convicções pessoais. Ou seja, de certezas que as pessoas trazem consigo e, em alguns casos, sequer se dão conta disso. Pode decorrer, além do mais, de acordos sociais; consensos.

Ancorado nestas balizas, a Filosofia classifica as teorias da verdade, basicamente, em 3 (três) categorias: a) verdade por correspondência; b) verdade pragmática; e,c) verdade consensual. ${ }^{4}$

A seguir, serão examinadas cada uma.

\section{Verdade por Correspondência}

De modo geral, diz-se que algo é verdadeiro quando se pode constatar, comprovar, certificar. Daí os vocábulos verificar, averiguar, cuja origem etimológica remete à verdade. Nesta métrica, verdadeiro é aquilo que se pode aferir e comprovar quanto a determinado objeto. Se alguém diz que, neste momento, a temperatura local está acima dos $35^{\circ}$ Celsius, a afirmação poderá ser testada com um termômetro. Após a checagem, será possível dizer se a afirmação era falsa ou verdadeira. A verdade por correspondência abarca esta compreensão. Para a verdade por correspondência algo será verdade se houver correlação entre ideia e objeto.

A verdade por correspondência remonta à Grécia Clássica. Foi Aristóteles (2005, p. 179) quem a sistematizou, nos seguintes termos: "falso é dizer que o ser não é ou que o não-ser é; verdadeiro é dizer que o ser é e que o não-ser não é. Consequentemente, quem diz de uma coisa que é ou que não é, ou dirá o verdadeiro ou dirá o falso". 
Sobre o tema, dois pontos devem ser assinalados. O primeiro reside no fato de que a ideia de correspondência tem como pressuposto um padrão referencial de comunicação (linguagem). Somente será possível certificar a correspondência entre enunciado e realidade se houver, previamente, uma linguagem entre os sujeitos (CARVALHO, 2009, p. 25). É a linguagem que permite a interação homogênea das impressões pessoais no que tange ao objeto verificado.

O segundo está no fato do exame da verdade por correspondência estar limitado por nossos sentidos, mesmo quando auxiliados por instrumentos avançados. Atento a isto, Kant (2009, p. 37) entendia que o ser humano, marcado por limites sensoriais, só tem acesso àquilo que ele designou de fenômenos (realidade cognoscível), mas não aos nôumenos (essência das coisas). Portanto, a coisa em si (verdade pura) é inalcançalvel e impenetrável aos humanos.

Em síntese: verdade por correspondência é aquela que guarda simetria entre a designação de algo e a existência efetiva deste algo no plano real.

\section{Verdade Pragmática}

A verdade pragmática tem raízes no pragmatismo estadunidense. O pragmatismo surgiu das reflexões de dois filosófos norte-americanos: Charles S. Peirce (1839-1914) e William James (1842-1910). Em linhas gerais, foi elaborado em oposição ao racionalismo, principalmente por este desprezar a experiência dos sentidos.

O vocábulo pragmatismo foi utilizado pela primeira vez por Peirce em 1878, no artigo Como tornar nossas ideias claras. Peirce defendia que o mecanismo da mente transforma o conhecimento, mas nunca pode criá-lo. O pensamento é movido pela dúvida e esta somente cessa quando se atinge a crença. Crença é a certeza de que algo é de tal modo para o sujeito a ponto de lhe serenar os ânimos.

A crença, por seu turno, desencadeia determinados comportamentos nos indíviduos, os quais se transformam em hábitos. Para Peirce ([2000?], p. 9) “a essência da crença é a criação de um hábito”.

Nestes termos, pragmática, do grego pragmatikós, indica ação, prática, hábito, pelo que uma ação, baseada em uma crença, se praticada repetidas vezes, torna-se um hábito e, com o tempo, converte-se em uma verdade. Por este ângulo, a verdade consiste em crenças que ensejam ações que se tornam hábitos. Para o pragmatismo pouco importa se a verdade está na razão ou na emoção, na ciência ou na religião, na filosofia ou na mitologia. O que importa é a crença do sujeito de que algo é verdadeiro.

\footnotetext{
${ }^{4}$ É de bom alvitre lembrar que existem outras teorias da verdade, caso da verdade por coerência e da verdade deflacionária, as quais excedem aos objetivos deste artigo, razão pela qual não serão abordadas adiante.
} 
Outro componente expressivo para o pragmatismo é a utilidade. A verdade de algo depende do quanto ela é útil ao sujeito (BUCKINGHAM, 2011, p. 208). Foi fundado nisto que James (1995, p. 30) afirmou: "verdadeiro é o nome de algo que, por si mesmo, é bom enquanto crença".

Nestas condições, para o pragmatismo não haveria problema se os hashis, com os quais os japoneses realizam suas refeições, fossem utilizados por ocidentais para fixação de cabelos longos ou como adornos em mesas de escritórios. O importante é a crença, o hábito que daí resulta e a utilidade do objeto na finalidade proposta. Se tais elementos estiverem presentes, então isto passa a ser uma verdade para o sujeito (JAMES, 1995, p.90).

Como se percebe, a verdade pragmática é algo interno no sujeito; é a verdade formada a partir de suas convicções e depende de seus valores e costumes. Trata-se de uma verdade que varia de sujeito para sujeito.

Em uma palavra, a verdade pragmática é relativa.

\section{Verdade Consensual}

A verdade consensual emanou do pensamento de Jürgen Habermas (1929-_). Segundo Habermas, e como já averbado linhas atrás, a verdade por correspondência depende da linguagem para atingir seu desígnio. Sem linguagem não há possibilidade de diálogo entre os comunicantes. Sem diálogo não há entendimento, não há consenso; não há verdade. Será a linguagem que levará os sujeitos do diálogo à mútua compreensão, ao assentimento recíproco, ao acordo sobre o que deve ser aceito como verdade (ARAGÃO, 1997, p. 82).

A verdade, sob esta rubrica, deixa de se concentrar na busca de exatidão entre ideia e objeto e passa a mirar na concordância dos sujeitos acerca do objeto. Torna-se decorrência da interação comunicativa entre, no mínimo, dois sujeitos. Esta comunicação dependerá da capacidade destes sujeitos de agir e de falar. Por isso, ao se fazer referência à verdade consensual, tem-se por pressuposto a razão comunicativa e a ação comunicativa. Pela razão comunicativa são estabelecidas condições universais para o entendimento, ao passo que pela ação comunicativa será possível a construção social da verdade, por meio de um processo argumentativo que conduza ao consenso sobre algo (HABERMAS, 1997, p. 418). ${ }^{5}$

A teoria de Habermas, neste compasso, manifesta-se como uma continuidade dos jogos de linguagem de Wittgenstein (1889-1951) e da Teoria dos Atos da Fala de John Langshaw Austin (1911-1960).

Wittgenstein (1997, p. 27-72) formulou seu conceito de jogos de linguagem em analogia aos jogos de xadrez. Defendeu que as palavras não têm sentido fixo no tempo e no espaço; ao contrário, dependem do

\footnotetext{
${ }^{5}$ Cumpre anotar que não se pretende aqui discorrer sobre a teoria do discurso de Habermas, até porque esta não é objeto de análise no artigo, como evidenciado na introdução. A referência feita no texto, portanto, teve apenas o intuito de registrar sua ligação com a teoria da verdade.
} 
contexto em que são empregadas para serem compreendidas. Podem variar de significado conforme as circunstâncias em que são utilizadas. Assim, para restringir o alcance de certas expressões e permitir a fluência da comunicação, o Wittgenstein trabalhou com outro conceito, por ele designado de semelhanças de família.

Segundo Wittgenstein, para esclarecer o que vem a ser um jogo ou precisamente distinguir um jogo de tabuleiro de um jogo de cartas, será necessário apurar algumas características que sejam comuns e exclusivas em ambos os jogos. Será este procedimento que permitirá identificar qual jogo estará sendo mencionado no momento. A mera palavra jogo será insuficiente neste intento. É preciso perscrutar o contexto em que a palavra jogo está sendo veiculada (jogos de linguagem) e as semelhanças de família existentes em determinada comunidade linguística para se saber, na situação concreta, de qual jogo se trata.

Ao trabalhar com os conceitos de jogos de linguagem e de semelhanças de família, Wittgenstein pôs a pragmática antes da semântica. Vale dizer, somente se poderá saber o significado de um vocábulo conforme o contexto em que este foi inserido. Esta postura influenciou o pensamento de Habermas, que formulou sua teoria da verdade consensual segundo a noção de uma pragmática universal. A pragmática universal seria uma espécie de pragmática inserida no cenário público e social.

Para melhor apreender este tema, deve-se ter presente a contribuição de John L. Austin à filosofia da linguagem. Austin vislumbrou a linguagem não como mera finalidade descritiva ou designativa da realidade. Segundo ele, nem sempre as palavras (ou falas) são verdadeiras ou falsas simplesmente. Em muitos casos, o discurso tem função constitutiva (perlocucionária) da própria realidade. Em How to do things with words, Austin fornece vários exemplos para ratificar sua afirmação. É o caso do noivo que diz aceitar o cônjuge como legítima esposa; do testamenteiro que diz legar a seu irmão determinado relógio; do sujeito que opta em apostar determinada soma em dinheiro que irá chover no dia seguinte, ou da exclamação que diz batizar um navio com o nome Rainha Elizabeth (AUSTIN, 1975, p. 05-07). Em todas estas situações, não há tom informativo ou descritivo nas falas. Há, sim, enunciados performativos - do inglês to perform - que indicam ação. Tais atos são constitutivos da realidade.

A verdade, sob esta vertente, passa a ser entendida como uma construção social. Advém da argumentação entre os sujeitos, ou melhor, da ação comunicativa dos sujeitos integrantes do processo argumentativo constitutivo da verdade. A verdade não representa ou traduz a essência do objeto em si, e sim decorre do acordo dos sujeitos em relação ao objeto; do consenso sobre os predicados do objeto; da ação desencadeadora deste consenso (ALEXY, 2012, p.111).

Esse consenso, porém, está circunscrito a determinado tempo e local, estando aberto a novas construções, se necessário. Para novas construções, contudo, serão imprescindíveis novos argumentos, os quais 
poderão conduzir, não sem tensão, a outros consensos, e assim sucessivamente. Daí por que se diz que a verdade é mutável no tempo e no espaço (DELAMAR, 2005, p. 10).

Deve-se frisar que, ao se fazer referência à expressão consenso, não significa que este seja absoluto, no sentido de expressar opinião unânime da sociedade sobre algum objeto específico. Consenso, aqui, indica resultado do processo dialógico/dialético realizado entre grupos ou segmentos sociais, legitimados a se pronunciar sobre determinados temas com o objetivo de estabelecer referenciais - verdades consensuais essenciais ao fluxo social.

Por este motivo, Habermas reconhece não só o valor da pragmática da linguagem, mas também a força renovatória e constitutiva do conhecimento na e pela linguagem. A verdade é resultado de um processo dialógico e argumentativo, e não monológico ou impositivo. O discurso é a sede para a argumentação e a verdade resultará do entendimento que daí emergir. A linguagem não descreve apenas a realidade, mas constrói a verdade - ação comunicativa - no cenário sociocultural. A verdade é um constructo social derivada da compreensão e assentimento dos participantes do diálogo social.

A verdade consensual tem grande importância para o Direito, ao expor qual a compreensão, o entendimento, a conclusão sobre temas e institutos jurídicos no momento de sua interpretação e aplicação, do qual o intérprete, ordinariamente, não deve se afastar.

A verdade consensual aponta para o sentido dos vocábulos jurídicos, servindo como vetor interpretativo de elevado calibre no momento da formulação da solução jurídica do litígio.

A verdade consensual, não obstante seja mutável, não é relativa. É objetiva. Daí sua importância para a interpretação jurídica.

\section{AS TEORIAS DA VERDADE APLICADAS NA INTERPRETAÇÃO JURÍDICA}

As teorias da verdade podem ser aplicadas à interpretação jurídica, na medida em que fornecem critérios para realizar a interpretação, assim como para sindicar do resultado interpretativo.

Para a interpretação jurídica deve ser empregada a verdade consensual. É que a verdade consensual externa o entendimento vigente acerca de matérias jurídicas específicas e, desta forma, serve de suporte para o intérprete desenvolver sua atividade de significação em relação ao tema respectivo. Note-se que isto evita discussões intermináveis sobre certas questões, além de obstar resultados alicerçados em meros juízos de valor.

A título exemplificativo, lembre-se do conceito de morte; quando alguém pode ser dado como morto?

Pois bem. De acordo com o art. 3º, da Lei no 9.434, de 4 de fevereiro de 1997, que dispõe sobre remoção de órgãos, tecidos e partes do corpo humano para fins de transplante e tratamento, para uma pessoa ser apontada 
como morta será imprescindível que exista morte encefálica. Logo, pouco importa a falência do sistema cardiorrespiratório ou de qualquer outro órgão do corpo humano. Morte é morte encefálica.

Neste viés, a despeito de divergências que o tema possa ter nas esferas filosófica ou religiosa, para o Direito morte é morte encefálica. Este é o consenso vigente na comunidade jurídica. Há, portanto, uma verdade consensual sobre quando alguém pode, juridicamente, ser considerado morto. De consequência, qualquer interpretação que escape desta fronteira deverá recebida como inadequada juridicamente.

Por outro lado, a interpretação jurídica deve se afastar da verdade pragmática; da verdade que alberga crenças, convicções, valores do intérprete. Caso contrário, numa sociedade plúrima como é o Brasil, não haverá estabilidade jurídica.

Dois exemplos podem clarificar o que se almeja demonstrar. Trata-se de duas decisões judiciais. A primeira, guiada pela verdade pragmática; a segunda, pela verdade consensual.

A primeira decisão foi prolatada em 2007, pelo juiz Edilson Rumbelsperger Rodrigues, de Sete LagoasMG, e examinou a Lei no 11.340/06, mais conhecida como Lei Maria da Penha, editada com o escopo de coibir a violência doméstica e familiar contra a mulher em atendimento às diretrizes preconizadas pelo art. 226, da Constituição Federal. ${ }^{6}$

Sucede que, ao examinar o caso, o magistrado limitou-se a tecer comentários, de ordem estritamente pessoal, sobre a Lei Maria da Penha, a qual nominou de "conjunto normativo de regras diabólicas" e "de uma heresia manifesta". Em seu modo de ver, "a desgraça humana começou no Éden: por causa da mulher — todos nós sabemos — mas também em virtude da ingenuidade, da tolice e da fragilidade emocional do homem".

$\mathrm{Na}$ decisão, o juiz ainda anotou: "dou-me o direito de ir mais longe, e em definitivo! O mundo é masculino! A ideia que temos de Deus é masculina! Jesus foi Homem!”.

Mais adiante, não hesitou em criticar a conduta social feminina, ao dizer: "a mulher moderna — dita independente, que nem de pai para seus filhos precisa mais, a não ser dos espermatozoides — assim só o é porque se frustrou como mulher, como ser feminino".

Tais afirmações, na leitura do magistrado, foram suficientes para se declarar a inconstitucionalidade incidental da Lei no $11.340 / 06$, diante da ofensa ao princípio da isonomia e pela colisão frontal contra o $\$ 8^{\circ}$, do art. 226, da Constituição Federal.

Com o devido respeito ao magistrado e, nos limites da crítica acadêmica, não há como aceitar o raciocínio judicial levado a efeito. A sentença contém apenas opiniões do juiz (verdade pragmática) sobre a Lei

\footnotetext{
${ }^{6}$ SETE LAGOAS-MG (Comarca). Decisão interlocutória no processo de autos no 222.942-8/06. Sete Lagoas/Minas Gerais, 17 de fevereiro de 2007. Disponível em: <http://www.sbdp.org.br/arquivos/material/439_CNJdecisesdelae2ainstncias.pdf>. Acessado em 04 mar. 2017.
} 
Maria da Penha e sobre a mulher em sociedade. Não há qualquer menção ao fato correspondente, tampouco a orientações doutrinárias ou precedentes de tribunais sobre a matéria que alicercem suas afirmações.

Como se sabe, o magistrado exerce suas funções em nome do Estado, não estando autorizado a tomar seus valores como norteadores para proferir suas sentenças. O magistrado, no exercício da prestação jurisdicional, deve dizer o Direito, daí a máxima latina juris dicere, e não dizer suas predileções. O juiz, no exercício de suas atribuições funcionais, não é sequer reputado como pessoa fisica; é órgão estatal. O juiz é o Estado; Estado-juiz. Por conta disso, suas convicções devem ser irrelevantes na interpretação jurídica. $\mathrm{O}$ juiz deve buscar na comunidade jurídica a verdade consensual sobre a temática em foco para proceder à interpretação que irá dirimir a lide.

A antítese do julgamento anterior pode ser encontrada na decisão proferida pelo Tribunal de Justiça do Paraná, de relatoria do Desembargador Clayton de Albuquerque Maranhão, em 2016. No caso, o autor, após descrever acidente de trânsito e imputar culpa à ré pelo ocorrido, postulou, dentre outros, a condenação da ré pelos danos estéticos por ter sofrido lesões graves e ter ficado paraplégico.

Sucede que não há na lei uma definição precisa em relação a dano estético. A rigor, não há sequer previsão expressa quanto à sua indenizabilidade. Esta resulta de interpretação jurídica ampliativa do conceito de dano moral, que, por sua vez, caracteriza-se pela violação a direitos da personalidade.

Ao decidir o caso, Maranhão indicou textualmente o que devia ser entendido por dano estético, a fim de precisar se o fato poderia se subsumir a referida premissa jurídica. Observe a decisão:

Como é cediço, dano estético consiste em uma afronta à aparência do ofendido, não se restringindo às características morfológicas ou aos traços fisionômicos da vítima, tais como cicatrizes, deformidades ou perda de membros.

Envolve a imagem física da pessoa em todos os aspectos exteriorizados, como a voz, os movimentos de andar e gesticular ou outras expressões do comportamento. Ou seja, caracteriza-se como uma superveniente desarmonia corporal ou gestual da vítima, levandose em conta todos os aspectos físicos que lhe são próprios.

Ressalte-se, ainda, ser plenamente possível a cumulação de indenização por danos morais e estéticos, conforme preceitua a Súmula no 387 do STJ: 'É lícita a cumulação das indenizações de dano estético e dano moral'.

No caso, a vítima Danilo Rodrigues ficou acometida de paraplegia após o acidente de trânsito, circunstância que justifica a indenização em decorrência de dano estético, a qual foi arbitrada na sentença em $\mathrm{R} \$ 50.000,00$ (cinquenta mil reais). ${ }^{7}$

É de se notar que houve um processo de significação, de atribuição de sentido na decisão; houve a fixação de um conceito quanto à expressão dano estético para que a causa pudesse ser solucionada. Não houve mera aposição de exato alcance ou real significado do texto legal, até porque, como sublinhado, sequer há diç̧ão

\footnotetext{
${ }^{7}$ BRASIL. Tribunal de Justiça do Paraná. Apelação cível no 156570. Apelante: Anacleto Fernando Nazari. Apeladas: SAMP Construtora de Obras Ltda., Karine Laiol Rodrigues (representada) e Eliane Laiol. Relator: Desembargador Clayton de Albuquerque Maranhão. Curitiba, 8 de dezembro de 2016. Disponível em: <https://portal.tjpr.jus.br/jurisprudencia/j/12291657/Ac\%C3\%B3rd\%C3\%A3o-1569570-2>. Acessado em 03 mar. 2017.
} 
normativa expressa a dano estético nos textos tomados com suporte (CC, art. 186 c/c CF, art. 5º V). Houve, sim, um processo de interpretação, de imputação de sentido quanto a dano estético, a partir de textos normativos.

Não obstante a isto, a decisão pode ser objeto de inspeção. Pode-se apurar se a significação realizada pelo magistrado para elucidar o que deve ser entendido por dano estético está em sintonia com a verdade consensual no ambiente jurídico. Importa dizer: se está em conformidade com a orientação firmada por tribunais e doutrina. Ou se, ao contrário, trata-se de uma opinião, crença ou ponto de vista do magistrado; de uma verdade pragmática.

Nessa tarefa verificadora, pode-se constatar, sem muito esforço, que a decisão está em consonância com a verdade consensual dominante. Isto se torna patente após consultar respeitável obra sobre o assunto, de Teresa Ancona Lopes (2004, p. 46), para quem dano estético é "qualquer modificação duradoura ou permanente na aparência externa de uma pessoa, modificação que lhe acarreta um 'enfeamento' e lhe causa humilhações e desgostos, dando origem, portanto, a uma dor moral".

Há, pois, uma harmonia entre o significado atribuído pelo magistrado a dano estético e a diretriz doutrinária existente, o que confere legitimidade à decisão judicial.

De se observar, que ao proporcionar a qualquer interessado mecanismo de checagem da razoabilidade da interpretação, há uma aproximação da verdade por correspondência, tornando o processo de verificação mais objetivo em sua extensão e análise.

Dito isto, pode-se constatar que a verdade consensual, embora oriunda da Filosofia, se aplicada à interpretação jurídica, pode contribuir de maneira relevante para o estabelecimento de padrões universais e generalizantes de institutos jurídicos. Isto permite que fatos similares recebam tratamento jurídico uniforme, presentes certos pressupostos, o que fortalece a coerência e integridade do sistema jurídico, além de assentar o contéudo prospectivo da interpretação jurídica.

Cumpre ressaltar que a verdade consensual não é permanente ou absoluta. O consenso existente em determinado período e local não é perpétuo. Muito pelo contrário, está aberto à revisões, correções, adaptações, mediante processo argumentativo dialético e dialógico, erigidos em espaço democrático. A propósito, foi o que se deu com os danos morais.

Durante muito tempo, entendeu-se que os danos morais não deveriam ser indenizados, pois seria imoral indenizar a lesão com dinheiro. Ainda assim, gradualmente, doutrina e jurisprudência, em processo de ressignficação desse conceito jurídico, atentas à realidade subjacente, não só firmaram que os danos morais importavam em ofensa aos direitos da personalidade (vida, integridade física e psíquica, honra, intimidade, privacidade, imagem), como também deveriam ser indenizados. Esclareceu-se que a indenização, em casos tais, não teria o condão de restituir as partes ao estado anterior ao episódio danoso, razão pela qual não se cogitaria de 
ressarcimento pecuniário propriamente dito. A indenização, em se tratando de danos morais, teria a finalidade de compensar monetariamente a violação aos bens e interesses jurídicos em prol da vítima, entendimento que culminou por prevalecer. Nem por isto se trata de um conceito finalizado. Hoje, tem-se entendido que existem danos morais em sentido amplo danos morais em sentido estrito, estes últimos vem a ser subespécies daqueles, caso do próprio dano estético, assim como do dano existencial, dano à saúde, dano à imagem etc. (MIRAGEM, 2015, p. 200).

Isto indica que o Direito, tal como a vida, é dinâmico, carecendo de revisões para atender às mutações sociais. Entretanto, é preciso a existência de padrões racionais que preservem a organicidade do sistema jurídico, sobretudo porque a interpretação jurídica não é algo passivo, apático, mecânico. É algo vivo, contínuo e inevitável. Aliás, as próprias palavras mudam de significado com o tempo. Bons costumes, em 1917, data de início de vigência do Código Civil anterior, não contava com idêntico significado em 2003, data de início de vigência do atual Código Civil.

Neste cenário, as teorias da verdade podem auxiliar a interpretação do Direito ao fornecerem parâmetros consistentes para uma racionalidade jurídica neste processo perene e complexo. Com as teorias da verdade, a interpretação jurídica assume contornos objetivos, sem ser imutável ou relativa.

\section{CONCLUSÕES}

Do desenvolvimento do tema, foram extraídas as seguintes conclusões:

1. Interpretar o Direito consiste em atribuir significados aos vocábulos contidos em textos e institutos jurídicos a partir do contexto respectivo. A visão de que a interpretação do Direito corresponderia a extrair da lei seu exato alcance e real significado está superada, haja vista os avanços da filosofia da linguagem.

2. As palavras são vagas e ambíguas. Este aspecto reforça o papel do intérprete do Direito em imputar sentido aos vocábulos jurídicos, sobretudo quando se tratar de conceitos jurídicos abertos, caso dos princípios e dos conceitos jurídicos indeterminados.

3. Os métodos tradicionais da hermenêutica jurídica não apresentam hierarquia entre si. Isto possibilita certa margem de escolha de um método em vez de outro pelo intérprete. Todavia, conforme o método adotado, a solução jurídica poderá variar, o que pode encobrir opções pessoais do intérprete, além de favorecer um cenário de instabilidade jurídica.

4. Uma boa teoria é aquela que não varia na explicação dos fenômenos estudados; que apresenta modelos objetivos para sua aplicação; que não está sujeita às preferências ad hoc do intérprete para dar conta das perguntas que advierem. Uma boa teoria é dotada de estabilidade e, consequentemente, de credibilidade. 
5. Em linhas gerais, na Filosofia há 3 (três) espécies de verdade, a saber: a) verdade por correspondência; b) verdade pragmática; e, c) verdade consensual. A verdade por correspondência expressa a equivalência entre ideia e objeto. A verdade pragmática é fundada nas crenças do sujeito e na sua utilidade. A verdade consensual expressa uma concordância ampla na comunidade sobre determinado objeto, resultante de debates dialógicos e dialéticos travados democraticamente.

6. A verdade pragmática deve ser afastada do processo interpretativo do Direito. Ao se lastrear em elementos valorativos do intérprete coloca em risco a segurança jurídica e estabilidade das relações jurídicas.

7. A verdade que importa à interpretação jurídica é a verdade consensual. Neste cariz, deve o intérprete buscar o significado consensual vigente na comunidade jurídica sobre determinados vocábulos para desenvolver sua atividade. A verdade consensual expressa o sentido universal e genérico de institutos jurídicos, assegurando a higidez do sistema jurídico.

8. A aplicação da verdade consensual na interpretação jurídica disponibiliza ao intérprete método para empreender sua tarefa com objetividade. Além disso, proporciona a quaisquer interessados recursos para averiguar a razoabilidade do resultado interpretativo, no que se aproxima da verdade por correspondência.

9. Em que pese a verdade consensual reflita o entendimento predominante no tempo e no espaço sobre vocábulos e institutos jurídicos, não se trata de algo finalizado. A verdade consensual é resultado de uma construção social, de maneira que permanece aberta a revisões, correções, alterações, observando-se o debate argumentativo e democrático na esfera social. Logo, sua adoção não conduz à petrificação do Direito. Ao contrário, lapida-o sem perder a objetividade.

\title{
INTERPRETATION OF THE LAW AND TRUTH THEORIES
}

\begin{abstract}
To interpret the Law consists of attributing sense to the words presents in the normative texts. Nor for this the interpretation should be accomplished with base in the interpreter's personal faiths; on the contrary, it should be anchored in a solid juridical rationality. The methods of legal hermeneutics (grammatical, logical, historical, finalistic, systematic, etc.) do not present hierarchy among themselves, and this allows the interpreter to adopt one method instead of another, which may lead to different juridical solutions for the same case. The theories of truth (correspondence, pragmatics and consensual) provide elements for a juridical rationality in the interpretation of Law. The interpreter must seek the consensual truth in the juridical community regarding the institute examined. The pragmatic truth, constituted by the interpreter's beliefs, must be refuted. The theories of truth applied to the interpretation of Law assist the interpreter in his activity and provide firm references to assess the reasonableness of the interpretation performed.
\end{abstract}


Keywords: Interpretation of Law. Theories of Truth. Philosophy of Language.

\section{REFERENCIAS}

ALEXY, Robert. Teoría de la Argumentación Jurídica. Traducción Manuel Atienza e Isabel Espejo. 2a Ed. Madrid: Centro de Estudios Políticos y Constitucionales, 2012.

ARAGÃO, Lúcia Maria de Carvalho. Razão Comunicativa e Teoria Social Crítica em Jürgen Habermas. Rio de Janeiro: Tempo Brasileiro, 1997.

ARISTÓTELES. Metafísica. Livro IV, Volume II. Tradução de Marclo Perine. 2a ed. São Paulo: Loyola, 2005.

AUSTIN, John Langshaw. How to do things with words. 2a ed. Cambrige: Harvard University Press, 1975.

BLEICHER, Josef. Hermenêutica Contemporânea. Lisboa: Edições 70, 1992.

BOBBIO, Norberto. Teoria do Ordenamento Jurídico. 10a ed. Tradução de Maria Celeste Cordeiro Leite dos Santos. Brasília: UNB, 1999.

BUCKINGHAM, WILL et all. The Philosophy Book New York: DK Publishing, 2011.

CAPEZ, Fernando. Curso de Direito Processual Penal. 19a ed., Saraiva: São Paulo. 2012.

CARVALHO, Aurora Tomazini de. Curso de Teoria Geral do Direito. O construtivismo lógico-semântico. São Paulo: Noeses, 2009.

DEUTSCH, David. The Beginning of Infinity: explanations that transform the World. New York: Peguin Group, 2011.

DUTRA, Delamar José Volpato. Razão e Consenso em Habermas. Florianópolis: Editora da Universidade Federal de Santa Catarina, 2005.

ECO, Umberto. Kant e o Ornitorrinco. Tradução de Ana Thereza B. Vieira. Rio de Janeiro: Record, 1997.

HABERMAS, Jürgen. Teoria de la Acción Comunicativa: Complementos y estudios previos. Traducción de Manuel Jiménez Redondo. 3a Ed. Madrid: Catedra, 1997.

JAMES, William. Pragmatism. New York: Dover Publications, 1995.

KANT, Immanuel. Crítica da Razão Pura. Tradução de Lucimar A. Gochi Anselmi e de Fulvio Lubisco. São Paulo: Martin Claret, 2009.

KIRKHAM, Richard L. Theories of Truth. A Critical Introduction. Cambridge (UK): Massachusetts Institute of Technology, 1995. 
LOPEZ, Teresa Ancona. Dano Estético. São Paulo: Revista dos Tribunais, 2004.

MIRAGEM, Bruno. Direito Civil. Responsabilidade Civil. São Paulo: Saraiva, 2015.

MONTESQUIEU, Charles-Louis de Secondat, Baron de la Brède et de. De L’Esprit des Lois. Livre XI, Chapitre IV. Paris: Librairie Ch. Delagrave, 1892.

PEIRCE, Charles Sanders. Como Tornar as Nossas Ideias Claras. Tradução de António Fidalgo. Lusofia Press. $[\mathrm{s} / \mathrm{d}]$.

RAMALHO, Barão de. Cinco Lições de Hermenêutica Jurídica. Clássicos do Direito Brasileiro. São Paulo: Saraiva, 1984.

SICHES, Luíz Recásens. Nueva Filosofia de la Interpretación del Derecho. 2a ed. México: Porrúas, 1973.

WITTGENSTEIN, Ludwig. Investigações Filosóficas. Tradução de José Carlos Bruni. São Paulo: Nova Cultural, 1999.

Trabalho enviado em 11 de março de 2017.

Aceito em 29 de junho de 2017. 